\title{
Hubungan Penggunaan Media Pembelajaran Grafis dengan Hasil Belajar Matematika Siswa Kelas IV
}

\author{
Dwi Anggraeni Siwi ${ }^{1)}$ Moefty Mahendra ${ }^{2)}$ \\ ${ }^{1}$ PGSD, Univet Bantara Sukoharjo \\ Deanggraenny@yahoo.com \\ ${ }^{1}$ PGSD, Univet Bantara Sukoharjo \\ mahendramoefty@yahoo.com
}

\begin{abstract}
Abstrak
Tujuan penelitian ini untuk mengetahui hubungan penggunaan media pembelajaran grafis dengan hasil belajar matematika siswa kelas IV Sekolah Dasar Negeri 01 Tengklik Kecamatan Tawangmangu Kabupaten Karanganyar Tahun Pelajaran 2017/2018. Jenis penelitian ini menggunakan kuantitatif dengan pendekatan korelasi yaitu menghubungkan antara variabel penggunaan media pembelajaran grafis dan variabel hasil belajar siswa. Populasi dalam penelitian ini adalah siswa kelas IV Sekolah Dasar Negeri 01 Tengklik Kecamatan Tawangmangu Kabupaten Karanganyar Tahun Pelajaran 2017/2018 yang berjumlah 24 siswa dan semua dijadikan sample penelitian. Metode pengumpulan data dalam penelitian ini menggunakan metode angket, tes dan dokumentasi. Teknik analisis yang digunakan adalah analisis statistik dengan korelasi product moment. Hasil analisis data diperoleh nilai sebesar 0,708 hasil tersebut lebih besar dari pada $\mathrm{N}=24$ taraf signifikansi $5 \%$ adalah 0,404 dan $1 \%$ yaitu 0,515 atau $0,708>0,404>0,515$. Maka hipotesis nol (Ho) ditolak sedangkan hipotesis alternatif (Ha) diterima. Dengan demikian hasil penelitian ini dapat disimpulkan bahwa ada hubungan yang signifikan antara penggunaan media pembelajaran grafis dengan hasil belajar matematika Siswa Kelas IV Sekolah Dasar Negeri 01 Tengklik Kecamatan Tawangmangu Kabupaten Karanganyar Tahun Pelajaran 2017/2018.
\end{abstract}

Kata Kunci : media pembelajaran grafis, hasil belajar, matematika

\begin{abstract}
The purpose of this study was to determine the relationship between the use of graphic learning media and the mathematics learning outcomes of the fourth grade students of Tengklik State Elementary School 01 Tawangmangu Subdistrict, Karanganyar District, 2017/2018 Academic Year. This type of research uses quantitative with a correlation approach that connects the variables of the use of graphic learning media and student learning outcomes variables. The population in this study were fourth grade students of Tengklik State Elementary School 01 Tawangmangu Subdistrict, Karanganyar District 2017/2018 Academic Year, totaling 24 students and all of them were used as research samples. Data collection methods in this study use questionnaire, test and documentation methods. The analysis technique used is statistical analysis with product moment correlation. The results of the data analysis obtained a value of 0.708 results are greater than $\mathrm{N}=24$ significance level of $5 \%$ is 0.404 and $1 \%$ is 0.515 or $0.708>0.404>0.515$. Then the null hypothesis $(\mathrm{Ho})$ is rejected while the alternative hypothesis $(\mathrm{Ha})$ is accepted. Thus the results of this study can be concluded that there is a significant relationship
\end{abstract}


between the use of graphic learning media and the mathematics learning outcomes of Grade IV students of Tengklik State Elementary School 01 Tawangmangu District, Karanganyar District 2017/2018 Academic Year.

Keywords: graphic learning media, learning outcomes, mathematics

\section{PENDAHULUAN}

Pendidikan adalah usaha sadar untuk menumbuh kembangkan potensi Sumber Daya Manusia (SDM) melalui kegiatan pengajaran. Kegiatan pengajaran tersebut diselengarakan pada semua satuan dan jenjang pendidikan yang meliputi wajib belajar pendidikan dasar 9 tahun, pendidikan menengah dan pendidikan tinggi. Menurut undang-undang Sistem Pendidikan Nasional Nomor 20 Tahun 2003 pada pasal 1 ayat 1 bahwa pendidikan adalah usaha sadar dan terencana untuk mewujudkan suasana belajar dan proses pembelajaran agar peserta didik secara aktif mengembangkan potensi dirinya untuk memiliki kekuatan spiritual keagamaan, pengendalian diri, kepribadian, kecerdasan, akhlak mulia, serta ketrampilan yang diperlukan dirinya, masyarakat, bangsa, dan negara. Pendidikan dasar merupakan salah satu pendidikan yang dilaksanakan di Sekolah Dasar (SD). Proses belajar di SD diadakan dengan sistem pembelajaran yang berisi serangkaian peristiwa yang dirancang, disusun sedemikian rupa untuk mendukung dan mempengaruhi proses belajar. Pembelajaran yang dilaksanakan di SD harus sesuai dengan kurikulum yang berlaku.

Matematika merupakan salah satu bidang studi yang ada pada semua jenjang pendidikan mulai dari tingkat sekolah dasar sampai perguruan tinggi. Menurut Permendiknas No. 22 Tahun 2006 salah satu tujuan matematika sekolah dasar adalah agar siswa memiliki kemampuan memahami konsep matematika, menjelaskan keterkaitan antar konsep dan mengaplikasikan konsep secara luwes, akurat, efisien, serta tepat dalam pemecahan masalah.

Oleh karena itu, matematika sebagai ilmu dasar perlu dikuasai dengan baik oleh siswa, terutama sejak usia sekolah dasar. Matematika merupakan salah satu mata pelajaran yang selalu identik dengan angka, rumus-rumus, dan matematika adalah ilmu pasti. Banyak siswa yang selalu berangapan mata pelajaran matematika 
merupakan salah satu pelajaran yang sulit. Sehingga banyak siswa yang kurang tertarik terhadap mata pelajaran matematika, hal ini dapat berpengaruh terhadap hasil belajar siswa.

Menurut Nawawi (Susanto, 2013) hasil belajar adalah kemampuan yang diperoleh siswa setelah melalui kegiatan belajar. Maka guru perlu mengetahui faktor apa saja yang mempengaruhi kesulitan belajar matematika yang dialami oleh siswa, dan memberikan solusi untuk meningkatkan hasil belajar matematika, karena apabila kesulitan belajar ini tidak diatasi akan menyebabkan prestasi hasil belajar yang rendah. Upaya mengatasi kesulitan belajar tersebut, maka penggunaan media dalam proses pembelajaran sangat diperlukan. Media pembelajaran sangat penting sehingga harus diterapkan dalam proses pembelajaran, karena banyak hasil penelitian yang menunjukkan bahwa proses pembelajaran akan lebih berhasil apabila siswa turut aktif dalam pembelajaran tersebut, dan hal ini hanya dapat terjadi dengan adanya media. Proses pembelajaran yang terjadi di sekolah dinilai sangat monoton atau membosankan karena guru menyampaikan informsi kepada siswa hanya dengan berbicara (verbalisme). Keterbatasan komunikasi dengan katakata sering menimbulkan kesulitan dalam menyampaikan bahan pelajaran kepada peserta didik. Kadang guru tidak sadar dengan kata-kata yang diucapkannya tanpa memperhatikan muridnya. Hal ini dapat mengakibatkan murid-murid pasif. Penyampaian materi yang berasal dari pengalaman nyata itu diperlukan penganti yaitu dengan mengikutsertakan media pembelajaran dalam proses belajar mengajar.

Berdasarkan hasil observasi yang dilakukan pada siswa kelas IV di SD Negeri 01 Tengklik Tawangmangu Karanganyar, masih banyak siswa yang belum mengerti atau memahami dengan materi yang diberikan oleh guru bisa dilihat dari hasil belajar 24 siswa dan ada $45 \%$ yang nilainya belum mencapai KKM yang sudah ditentukan sekolah yaitu 70 terhadap pelajaran matematika dan kurang tertarik dengan pelajaranan khususnya mata pelajaran matematika karena guru belum memaksimalkan alat peraga dan media dalam proses pembelajaran. Melihat kondisi tersebut, hendaknya guru mampu mencari gagasan baru (inovasi) menyempurnakan pelaksanaan pembelajaran dengan menggunakan media pembelajaran (gambar, poster, bagan, dan diagram) media grafis. Menurut Anitah, (2012: 71) grafis atau 
gambar merupakan alat visual yang penting dan mudah didapat. Dikatakan penting sebab media grafis dapat mengganti kata verbal, mengongkritkan yang abstrak, dan mengatasi pengamatan manusia. Gambar yang membuat orang dapat menangkap ide atau informasi yang terkandung didalamnya dengan jelas, lebih jelas diungkapkan denagn kata-kata. Berdasarkan uraian diatas, penulis tertarik mengadakan penelitian dengan judul "Hubungan Penggunaan Media Pembelajaran Grafis Dengan Hasil Belajar Matematika Siswa Kelas IV Sekolah Dasar Negeri 01 Tengklik Kecamatan Tawangmangu, Kabupaten Karanganyar Tahun Pelajaran 2017/2018".

\section{METODE PENELITIAN}

Penelitian dilaksanakan di kelas IV Sekolah Dasar Negeri 01 Tengklik Kecamatan Tawangmangu Kabupaten Karanganyar. Adapun pemilihan Sekolah Dasar Negeri 01 Tengklik Kecamatan Tawangmangu Kabupaten Karanganyar.

Penelitian ini menggunakan metode penelitian kuantitatif. Pada penelitian kuantitatif ini menggunakan korelasi antara penggunaan media grafis dengan hasil belajar matematika. Sedangkan untuk variabel bebasnya penggunaan media grafis, variabel ini dijadikan variabel yang ikut mempengaruhi variabel terikat. Variabel penelitian adalah a.)Variabel Bebas (independent variable) yakni Penggunaan Media Pembelajaran Grafis dengan indikator yaitu pembelajaran dengan menggunakan media grafis, pelaksanaan pembelajaran menggunakan media bagan, pelaksanaan pembelajaran menggunakan media gambar, pelaksanaan pembelajaran menggunakan media kartun. b)Variabel Terikat (dependent variable) yakni Hasil Belajar Matematika Siswa Kelas IV SD Negeri 01 Tengklik Kecamatan Tawangmangu Kabupaten Karanganyar. Hasil belajar diambil dari nilai tes matematika materi bangun datar dengan indikator yaitu menjelaskan sifat bangun datar persegi, persegi panjang, dan segitiga, menentukan rumus luas dan keliling persegi, persegi panjang dan segitiga, menghitung luas dan keliling bangun datar dalam gambar, memecahkan masalah yang berhubungan dengan keliling dan luas bangun datar persegi, persegi panjang dan segitiga. 
Metode dan instrumen pengumpulan data yang dipergunakan dalam penelitian ini adalah angket atau kuesioner.

\section{HASIL DAN PEMBAHASAN}

\section{a. Hasil Penlitian}

Data hasil penelitian diperoleh melalui proses penelitian yang telah dilakukan oleh penulis yaitu pada hari Kamis tanggal 26 April 2018 sampai hari Jum'at 27 April 2018 dengan subjek penelitian guru dan siswa serta obyek penelitian media grafis dan hasil belajar matematika siswa kelas IV Sekolah Dasar Negeri 01 Tengklik Kecamatan Tawangmangu Kabupaten Karanganyar yang berjumlah 24 siswa.

Pengumpulan data pada penelitian ini dalam pelaksanaannya dilakukan oleh penulis sendiri dengan metode angket atau kuensioner, tes, dan dokumentasi. Metode tes diperoleh dari nilai hasil belajar matematika soal obyektif materi bangun datar dan metode dokumentasi digunakan untuk mengumpulkan data yang berhubungan dengan variabel penelitian. Adapun metode angket yang digunakan dalam penelitian ini untuk mengumpulkan data mengenai penggunaan media pembelajaran grafis. Bentuk persentase yang sesuai dengan kategori, lebih jelasnya penulis sajikan dalam tabel sebagai berikut:

Tabel 1. Data Persentase Penggunaan Media Pembelajaran Grafis

\begin{tabular}{llll}
\hline $\begin{array}{l}\text { Penggunaan Media } \\
\text { Pembelajaran grafis }\end{array}$ & Interval & Frekuensi & Presentase \\
\hline Baik & $76-87$ & 11 & $45,84 \%$ \\
\hline Cukup & $67-75$ & 8 & $33,33 \%$ \\
\hline Kurang & $57-66$ & 5 & $20,83 \%$ \\
\hline & & 24 & $100 \%$ \\
\hline
\end{tabular}

Dari tabel di atas, dapat diketahui bahwa Penggunaan Media Pembelajaran Grafis Siswa Kelas IV Sekolah Dasar Negeri 01 Tengklik Kecamatan Tawangmangu Kabupaten Karanganyar Tahun Pelajaran 2017/2018 yang berjumlah 24 siswa berdasarkan tabel presentase menunjukan 
45,84\% dapat dikategorikan bahwa penggunaan media pembelajaran grafis siswa pada kriteria baik.

Sedangkan data tentang hasil belajar siswa diperoleh dari nilai tes 20 soal obyektif mata pelajaran matematika materi bangun datar Semester II. Secara keseluruhan data tentang hasil belajar siswa kelas IV Sekolah Dasar Negeri 01 Tengklik Kecamatan Tawangmangu Kabupaten Karanganyar Tahun Pelajaran 2017/2018 disajikan dalam lampiran 9. Data tentang hasil belajar siswa kelas IV Sekolah Dasar Negeri 01 Tengklik Kecamatan Tawangmangu Kabupaten Karanganyar Tahun Pelajaran 2017/2018, nilai yang paling tinggi adalah 95 dan yang paling rendah adalah 75, semua nilai dari 24 siswa sudah memenuhi Kriteria Ketuntasan Minimum (KKM) untuk mata pelajaran matematika yaitu 70. Jadi, dapat diketahui bahwa hasil belajar siswa kelas IV Sekolah Dasar Negeri 01 Tengklik Kecamatan Tawangmangu Kabupaten Karanganyar Tahun Pelajaran 2017/2018 dengan kriteria baik.

\section{b. Pembahasan}

Berdasarkan hasil penelitian dan analisis data yang telah dilakukan menunjukan bahwa ada hubungan yang signifikan antara penggunaan media pembelajaran grafis dengan hasil belajar siswa. Hal ini dapat dilihat berdasarkan hasil hitung diperoleh bahwa nilai rhitung=0,708, sedangkan nilai $\mathrm{r}_{\text {tabel }}$ (ts) 5\% dan (ts) 1\% masing-masing sebesar 0,404 dan 0,515. Dengan demikian, $r_{\text {hitung }}$ lebih besar dari $r_{\text {tabel }}\left(r_{\text {hitung }}>r_{\text {tabel }}\right)$ maka hipotesis alternative (Ha) yang berbunyi “Ada hubungan yang signifikan antara penggunaan media pembelajaran grafis dengan hasil belajar matematika Siswa Kelas IV Sekolah Dasar Negeri 01 Tengklik Kecamatan Tawangmangu Kabupaten Karanganyar Tahun Pelajaran 2017/2018”. Diterima atau disetujui dan hipotesis nol (Ho) yang berbunyi “ Tidak adahubungan yang signifikan antara penggunaan media pembelajaran grafis dengan hasil belajar matematika Siswa Kelas IV Sekolah Dasar Negeri 01 Tengklik Kecamatan Tawangmangu Kabupaten Karanganyar Tahun Pelajaran 2017/2018" ditolak. Maka terbukti kebenaran dari pendapat Sadiman (Suyahman \& Pranowo, 2018: 39) media adalah perantara atau 
pengantar pesan dari pengirim ke penerima pesan. Secara lebih khusus, pengertian media dalam pembelajaran diartikan sebagai alat-alat grafis, fotografis, atau elektronis untuk menangkap, memproses, dan menyusun kembali invormasi visual atau verbal.

Media juga dapat diartikan sebagai segala sesuatu yang digunakan untuk menyalurkan pesan serta dapat merangsang pikiran, perasaan, perhatian, dan kemauan peserta didik untuk belajar sehingga dapat mendorong terjadinya proses belajar serta menjadikan tujuan pembelajaran dapat dicapai dengan mudah. Media pembelajaran grafis digunakan sebagai media mengasah kemampuan berfikir anak. Siswa akan tertarik dan mempermudah mengingat materi ketika pembelajaran berlangsung yang disampaikan oleh guru. Penerapan strategi dan media pembelajaran yang baik dapat membankitkan minat dan hasil belajar matematika siswa. Oleh karena itu, dengan adanya media pembelajaran grafis dapat mempermudah dalam penyampaian materi pembeljaran khususnya pada mata pelajaran matematika, media pembelajaran menjadi media yang efektif dan siswa lebih mudah memahami materi pembelajaran sehingga hasil belajar siswa lebih meningkat.

\section{SIMPULAN}

Berdasarkan data-data yang telah dikumpulkan dan dari hasil penelitian sebagaimana yang telah diuraikan pada bab terdahulu maka dapat ditarik kesimpulan sebagai berikut: Terdapat hubungan yang signifikan antara penggunaan media pembelajaran grafis dengan hasil belajar matematika Siswa Kelas IV Sekolah Dasar Negeri 01 Tengklik Kecamatan Tawangmangu Kabupaten Karanganyar Tahun Pelajaran 2017/2018. Hal ini dibuktikan dari hasil perhitungan statistik dengan rumus korelasi product momen yang diperoleh nilai koefisien 'hitung 0,708, nilai $\mathrm{r}_{\text {tabel }}$ masing-masing pada taraf signifikan 5\% maupun $1 \%$ sebesar 0,404 dan 0,515. 


\section{DAFTAR PISTAKA}

Anitah, Sri. 2012. Media Pembelajaran. Surakarta: Yuma Pustaka.

2014. Media Pembelajaran. Surakarta: UPT Penerbit dan UNS Press.

Arikunto, Suharsimi. 2010. Prosedur Penelitian. Jakarta: Rineka Cipta.

Budiyono, dkk. $2018 . \quad$ http:// tpcommunity.blogspot.com/2018/03/strategimemanfaatkan- mediagambar: htm.

Daryato. 2013. Media Pembelajaran. Surakarta: Gava Media.

Gunawan. Muhamad Ali. 2008. Setatistik Untuk Penelitian Pendidikan. Yogyakarta: Parama Publishing.

Ismail.2011. Penelitian Pendidikan. Sukoharj0: Univet Bantara Press.

Mertina, Datuarruan. Peran Media Gambar IPS Terhadap Hasil Belajar Siswa. Jurnal: Kreatif Tadulako Vol. 1 No. 1 ISSN 2354-614X. Munandi,Yudhi. 2008. Media Pembelajaran. Jakarta:Gaung Persada Press.

Nurul, Fitri. 2014. Pengaruh penggunaan Media Grafis (Gambar) Terhadap Hasil Belajar Siswa Pada Mata Pelajaran Pendidikan Agama Islam. Tesis tidak diterbitkan. Jakarta: UIN.

Pitro, Eko. 2015. Teknik Penyusunan Instrumen Penelitian. Yogyakarta: Pustaka Pelajar

Priyono. 2017. Pengaruh Penggunaan Media Grafis Komik Terhadap Hasil Prestasi Belajar IPA. 2018. Jurnal Paedagogia.Vol.20 No.1/Febuari 2018.

Suyahman. Pranowo. 2018. Media Pembelajaran PPKn SD. Usaha Mandiri.

Susanto, Ahmad.2013. Teori Belajar \& Pembelajaran. Jakarta: Prenada Media Group.

Sugiyono. 2010. Metode Penelitian Kuantitatif Kualitatif Dan $R \&$ D. Bandung: Alfabeta. . 2014. Metode Penelitian Kuantitatif Kualitatif Dan $R \&$ D. Bandung: Alfabeta.

Siti, Maisyaroh. 2012. Penggunaan Media Grafis Pada Pembelajaran Pendidikan Kewarganegaraan. Jurnal: Kreatif Tandulako. Vol. 4 No.1 
Suratmi. 2013. The Influence of the Use of Graphic Media. Jurnal: Scienti. Vol. 2 No.2/November 2013. 